\title{
Article \\ Iron-Nickel Alloy with Starfish-like Shape and Its Unique Magnetic Properties: Effect of Reaction Volume and Metal Concentration on the Synthesized Alloy
}

\author{
Norhan Nady ${ }^{1, *(\mathbb{D}}$, Noha Salem ${ }^{2}$, Marwa A. A. Mohamed ${ }^{3}$ and Sherif H. Kandil ${ }^{2}$ \\ 1 Polymeric Materials Research Department, City of Scientific Research and Technological \\ Applications (SRTA-City), New Borg El-Arab City, Alexandria 21934, Egypt \\ 2 Department of Materials Science, Institute of Graduate Studies and Research, Alexandria University, \\ Alexandria 21526, Egypt; noha.salem@yahoo.com (N.S.); s.kandil@usa.net (S.H.K.) \\ 3 Fabrication Technology Department, City of Scientific Research and Technological Applications (SRTA-City), \\ Borg El-Arab City, Alexandria 21934, Egypt; marwa945@yahoo.com \\ * Correspondence: norhan.nady77@yahoo.com; Tel.: +20-1090918521
}

\section{check for} updates

Citation: Nady, N.; Salem, N.; Mohamed, M.A.A.; Kandil, S.H. Iron-Nickel Alloy with Starfish-Like Shape and Its Unique Magnetic Properties: Effect of Reaction Volume and Metal Concentration on the Synthesized Alloy. Nanomaterials 2021, 11, 3034

https://doi.org/10.3390/nano11113034

Academic Editor: Julian Maria Gonzalez Estevez

Received: 24 October 2021

Accepted: 10 November 2021

Published: 12 November 2021

Publisher's Note: MDPI stays neutral with regard to jurisdictional claims in published maps and institutional affiliations.

Copyright: (c) 2021 by the authors. Licensee MDPI, Basel, Switzerland. This article is an open access article distributed under the terms and conditions of the Creative Commons Attribution (CC BY) license (https:// creativecommons.org/licenses/by/ $4.0 /)$.

\begin{abstract}
Iron-nickel alloy is an example of bimetallic nanostructures magnetic alloy, which receives intensive and significant attention in recent years due to its desirable superior ferromagnetic and mechanical characteristics. In this work, a unique starfish-like shape of an iron-nickel alloy with unique magnetic properties was presented using a simple, effective, high purity, and low-cost chemical reduction. There is no report on the synthesis of such novel shape without complex precursors and/or surfactants that increase production costs and introduce impurities, so far. The synthesis of five magnetic iron-nickel alloys with varying iron to nickel molar ratios (10-50\% $\mathrm{Fe})$ was undertaken by simultaneously reducing $\mathrm{Fe}(\mathrm{II})$ and $\mathrm{Ni}$ (II) solution using hydrazine hydrate as a reducing agent in strong alkaline media for $15 \mathrm{~min}$ at $95-98^{\circ} \mathrm{C}$. The effect of reaction volume and total metal concentration on the properties of the synthesized alloys was studied. Alloy morphology, chemical composition, crystal structure, thermal stability, and magnetic properties of synthesized iron-nickel alloys were characterized by means of SEM, TEM, EDX, XRD, DSC and VSM. ImageJ software was used to calculate the size of the synthesized alloys. A deviation from Vegard's law was recorded for iron molar ration higher than $30 \%$., in which superstructure phase of $\mathrm{FeNi}_{3}$ was formed and the presence of defects in it, as well as the dimensional effects of nanocrystals. The saturation magnetization (Ms), coercivity $(\mathrm{Hc})$, retentivity $(\mathrm{Mr})$, and squareness are strongly affected by the molar ratio of iron and nickel and reaction volume as well as the total metal concentration.
\end{abstract}

Keywords: starfish-like shape; iron-nickel alloy; magnetic properties; chemical reduction method

\section{Introduction}

In recent years, nanomaterials have begun to revolutionize the world as they provide new dimensions for research and development. Nanoparticles (NPs) are ultrafine particles with lengths ranging from 1 to $100 \mathrm{~nm}$ at least one dimension. They have a high surface-area-to-volume ratio, which enables them to exhibit different physical and chemical properties such as reactivity, versatility, and strength than their bulk counterparts [1,2]. Among various nanoparticle types, magnetic nanoparticles (MNPs) attracted increased attention due to their unique physicochemical and magnetic properties [3,4]. MNPs are potentially employed in many applications such as biomedicine [2,5], environmental remediation [1,4], catalysis [6,7], magnetic resonance imaging [8,9], data storage [10,11], sensors [12,13], electromagnetic shielding [14], and absorbing materials [15], etc.

The hysteresis loop has been used for characterizing the magnetic materials. One of the important magnetic properties is coercivity $(\mathrm{Hc})$, which is a measure of the ability of a ferromagnetic material to keep its magnetization (i.e., without being demagnetized) when 
exposed to an external magnetic field [16]. Ferromagnetic materials with high coercivity are called magnetically hard and are used to make permanent magnets [17]. Materials with low coercivity are known as soft magnetic materials, which are used in many applications such as transformers [18], recording heads [19], microwave devices [20], and magnetic shielding [21]. Another important magnetic parameter is the saturation magnetization (Ms), which is the maximum possible magnetization of ferromagnetic material, characterized by parallel orientation of all magnetic moments inside the material; it decides that the materials are hard or soft magnets. Remanence or Retentivity (Mr) is the remaining magnetization left after removing the material from a magnetic field. A hard magnetic material has high remanence and coercivity [22]. Another parameter used to describe the magnetic materials is receptivity $(\mathrm{Hr})$, which shows the willingness of the material to be magnetized. The ratio $\mathrm{Mr} / \mathrm{Ms}$, which is also called squareness ratio, measures how the square is the hysteresis loop and is a dimensionless quantity between zero and one. Its value depends on the target application; for example, it should be near 1 for memory devices, whereas it should be near zero for magnetic fluids.

Iron-nickel alloy is an example of bimetallic nanostructures magnetic alloy, which received intensive and significant attention in recent years due to its desirable superior ferromagnetic and mechanical characteristics that make it applicable in many fields [23-25]. $\mathrm{Fe}_{x} \mathrm{Ni}_{1-\mathrm{x}}$ alloy with $\mathrm{x}$ being in the range of $20-50 \%$ molar ratio is called Permalloy, known for its soft magnetization, and widely used for magnetic heads and environmental remediation [14]. An attractive feature of Fe-Ni alloy is that it can be prepared with different sizes, shapes, compositions, morphologies, and size distribution depending on the method used for the preparation [23,25,26] and iron-to-nickel composition in alloy [23]. A variety of morphological structures of iron-nickel alloy have been prepared including spherical particles [27], triangular particles [28], rods [29], wires [23], platelets [30], flower-like [31], and leaf-like particles [32].

Fabrication of iron-nickel alloyed micro-/nanoparticles has been achieved by various physical and chemical methods such as mechanical alloy [33], chemical reduction in solution [34], chemical vapor deposition [35], physical vapor deposition [36], sol-gel combined with hydrogen reduction [37], sol-gel combustion [38], vacuum evaporation [39], electroless plating [40], chemical reduction based on the polyol process [41], microemulsion method [42], hydrothermal reduction [43], etc. Most of these processes usually require complex precursors and/or surfactants, which increase production costs and introduce impurities, resulting in noticeable declines in the properties of the structures [44]. Thus, a simple and low-cost process for the large-scale preparation of pure nanocrystalline magnetic iron-based alloy remains challenging to researchers. Moreover, additional efforts are needed to control experimental conditions for the synthesis of magnetic nanoparticles with controlled shape, size, and magnetic properties.

The chemical reduction method has advantages over other methods including mildness, simplicity, low cost, and large-scale production [34], and has been adopted to successfully prepare some low-dimensional Fe-Ni alloy nanostructures including nanospheres [26] and polycrystalline nanorods [27]. However, the fabrication of Fe-Ni alloy nanostructures via a solution-phase chemical reduction approach still remains a challenge because the ferrous ion is easily oxidized iron oxides and tends to hydrolyze. By control of their properties through the manipulation of their physical and molecular structures, researchers have developed iron oxide nanoparticles to support a wide range of applications.

The starfish-like structure presented in this work is a novel Fe-Ni alloy microstructures/nanostructures and there is no report on the synthesis of it by chemical reduction method so far. This work documents the study of the effect of the volume of the reaction solution (preparation) on the purity and (magnetic) properties of Fe-Ni alloys, which represents the possibility of preparing the mixture on an industrial scale and in a very short preparation time without affecting the purity and properties of the resulting alloy. In this study, five nanostructured Fe-Ni alloys were synthesized with varying iron to nickel molar ratios $(10-50 \% \mathrm{Fe})$. The effect of the molar ratio between iron and nickel and total 
metal concentration as well as the reaction volume in the microstructure and the magnetic properties of the produced alloys was studied. Different analyses techniques such as SEM, TEM, EDX, XRD, DSC were used to observe the morphology and verify the composition of the synthesized alloys. ImageJ software was used to calculate the size of the synthesized alloys. Starfish-like $\mathrm{Fe}_{10} \mathrm{Ni}_{90}$ alloy, which has unique magnetic properties, was investigated and presented in this work.

\section{Materials and Methods}

\subsection{Materials}

The chemicals used for alloy synthesis include nickel chloride hexahydrate $\left(\mathrm{NiCl}_{2}\right.$. $\left.6 \mathrm{H}_{2} \mathrm{O}, 98 \%\right)$, Ferrous chloride tetrahydrate $\left(\mathrm{FeCl}_{2} \cdot 4 \mathrm{H}_{2} \mathrm{O}, 99.99 \%\right)$ as sources of metal ion was purchased from Sigma (Darmstadt, Germany). Hydrazine hydrate $\left(\mathrm{N}_{2} \mathrm{H}_{4} \cdot \mathrm{H}_{2} \mathrm{O}, 99 \%\right)$ was obtained from Fisher (Horsham, UK) as a reducing agent. Sodium hydroxide $(\mathrm{NaOH}$, 98\%) catalyst was purchased from trading dynamic co. TDC (Cairo, Egypt). Distilled water was used as a solvent.

\subsection{Methods}

Nanocrystalline of $\mathrm{Fe}_{10} \mathrm{Ni}_{90}, \mathrm{Fe}_{20} \mathrm{Ni}_{80}, \mathrm{Fe}_{30} \mathrm{Ni}_{70}, \mathrm{Fe}_{40} \mathrm{Ni}_{60}$, and $\mathrm{Fe}_{50} \mathrm{Ni}_{50}$ alloys were synthesized as follows: Aqueous solutions of $\mathrm{Fe}^{+2}, \mathrm{Ni}^{+2}$ ions of molar ratio 1:9, 2:8, 3:7, 4:6, and 5:5 were prepared by dissolving appropriate amounts of $\mathrm{FeCl}_{2} \cdot 4 \mathrm{H}_{2} \mathrm{O}$ and $\mathrm{NiCl}_{2} \cdot 6 \mathrm{H}_{2} \mathrm{O}$ in distilled water. The prepared solution was vigorously stirred on a magnetic stirrer equipped with a heating unit at 1400-1600 rpm and $95-98{ }^{\circ} \mathrm{C}$. The second solution of warm aqueous hydrazine, $\mathrm{N}_{2} \mathrm{H}_{4} \cdot \mathrm{H}_{2} \mathrm{O}$, (99 wt.\%), and aqueous $\mathrm{NaOH}(0.1 \mathrm{M})$ with pH 12.8 was added to the first solution. The volumetric ratio of $\mathrm{N}_{2} \mathrm{H}_{4} \cdot \mathrm{H}_{2} \mathrm{O} / \mathrm{NaOH}$ solutions was about 5:1. The molar ratio of hydrazine to metal ions was significantly higher than the stoichiometric one. The precipitation of fine black particles was the result of the reduction reaction. The final fabricated black particles were separated magnetically, then washed repeatedly with distilled water until neutral $\mathrm{pH}$ and dried in a vacuum oven at $35{ }^{\circ} \mathrm{C}$ for $24 \mathrm{~h}$. The experiment for each alloy was performed twice-once at small reaction volume (40 mL of aqueous solution) and the second was undertaken using a larger scale ( $80 \mathrm{~mL}$ of aqueous solution). Two metal concentrations were used in this work: 0.1 and $0.3 \mathrm{M}$ with large reaction volumes.

\subsection{Characterization}

\subsubsection{X-ray Diffraction (XRD) Analysis}

X-ray diffraction (XRD) was employed to characterize the synthesized alloys and determine their crystallite size and lattice parameter. XRD measurements were carried out on a Shimadzu XRD-7000 diffractometer (Kyoto, Japan, 45 kV, 30 mA; CuK $\alpha$ + Ni-filtered radiation, $\lambda=0.15406 \mathrm{~nm}$ ). The $2 \theta$ range was $5-80^{\circ}$, at a scanning rate of $4^{\circ} / \mathrm{min}$ and a scanning step of $0.026^{\circ}$.

\subsubsection{Scanning Electron Microscopy (SEM) Imaging and X-ray Spectroscopy (EDX) Analysis}

The morphology and particle sizes were analyzed by scanning electron microscopy (SEM, JEOL, Model JSM 6360 LA, Kyoto, Japan). SEM samples were prepared by dispersion of alloy particles on a cupper-support using a double face. The dispersed particles on the cupper-support were coated with Au before imaging. A voltage of $15 \mathrm{kV}$ and a resolution of $1280 \times 960$ pixels were used. Chemical compositions were estimated by an area analysis using energy-dispersive X-ray spectroscopy (EDX) system equipped with SEM. Particle size was calculated using SEM images by imageJ software.

\subsubsection{Scanning-Transmission Electron Microscope (STEM) Imaging and X-ray Spectroscopy (EDX) Analysis}

The particle morphology of the prepared alloys was inspected by high-resolution TEM (HREM) using a field emission electron-source scanning-transmission electron microscope 
(STEM) (JEOL 2010 F, Boston, MA, USA), operated at $200 \mathrm{kV}$. For the TEM investigations, the nanoparticles were deposited on a cupper-grid-supported transparent carbon foil. The sample was vigorously sonicated in ethanol for $15 \mathrm{~min}$ before deposition on the grade. Chemical compositions were estimated by an area analysis using an energy-dispersive X-ray spectroscopy (EDX) system equipped with STEM. Particle size, as well as the length of cones/needles, were calculated using STEM images by ImageJ software for starfish-like monocrystalline alloy.

\subsubsection{Vibrating Sample Magnetometer (VSM) Analysis}

A vibrating sample magnetometer (VSM, Lake Shore 7410, Boston, MA, USA) was used to measure the room-temperature magnetic properties of the prepared alloys. The applied field was $-20 \leq \mathrm{H} \leq 20 \mathrm{kOe}$. For magnetization measurements, the powder was pressed strongly and fixed in a small cylindrical plastic box.

\subsubsection{Differential Scanning Calorimeter (DSC) Analysis}

The thermal properties of the synthesized nanopowders were determined with differential scanning calorimetry (TA-4000 System Mettler, Auckland, New Zealand). A powder sample $(5 \mathrm{mg})$ was heated from room temperature $\left(27^{\circ} \mathrm{C}\right)$ to $50{ }^{\circ} \mathrm{C}$ under air nitrogen atmosphere at a rate of $10^{\circ} / \mathrm{min}$.

\section{Results and Discussion}

Iron-nickel alloys have been given attention because of a broad variety of magnetic properties that can be obtained by manipulating the composition and the used preparation method. In this work, nanostructured iron-nickel alloys were synthesized within 15 min reaction time and their affinity to a magnet is high for collection with a magnet, during the washing process as shown in Figure 1.

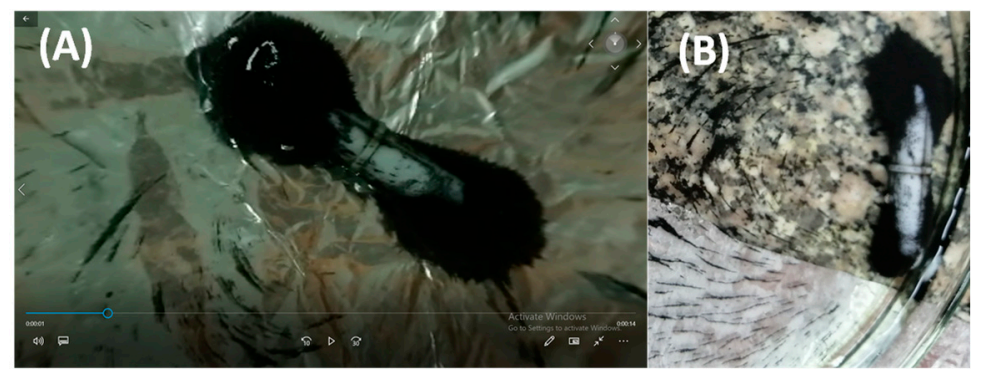

Figure 1. Photos of the prepared iron-nickel alloy during washing process $(\mathbf{A}, \mathbf{B})$.

\subsection{Alloy Morphology}

To obtain visual insight into the synthesized iron-nickel alloys, their morphologies were studied via the SEM and TEM techniques, shown in Figures 2 and 3. The SEM images suggest that the nanoparticles of all the prepared alloys tend to agglomerate together when deposited onto the cupper-support, which can be attributed to the tendency of the alloy particles to decrease the system energy because of its high surface free energy and the magnetostatic energy. The molar ratio $\mathrm{Fe}_{10} \mathrm{Ni}_{90}$ showed a completely different structured alloy than all the prepared alloys in which a unique starfish-like shape was captured. The clearer starfish-like shape with sides cones/needles was observed by SEM (Figure 2) with $0.3 \mathrm{M}$ and $80 \mathrm{~mL}$ reaction volume. This morphology neither changed with doubling the reaction volume nor with increasing the metal concentration ( 40 and $80 \mathrm{~mL}$ reaction volumes and 0.1 and $0.3 \mathrm{M}$ metal concentrations) as shown in both SEM (Figure 2) and TEM (Figure 3) images. 


\section{$0.1 \mathrm{M} 40 \mathrm{ml}$}
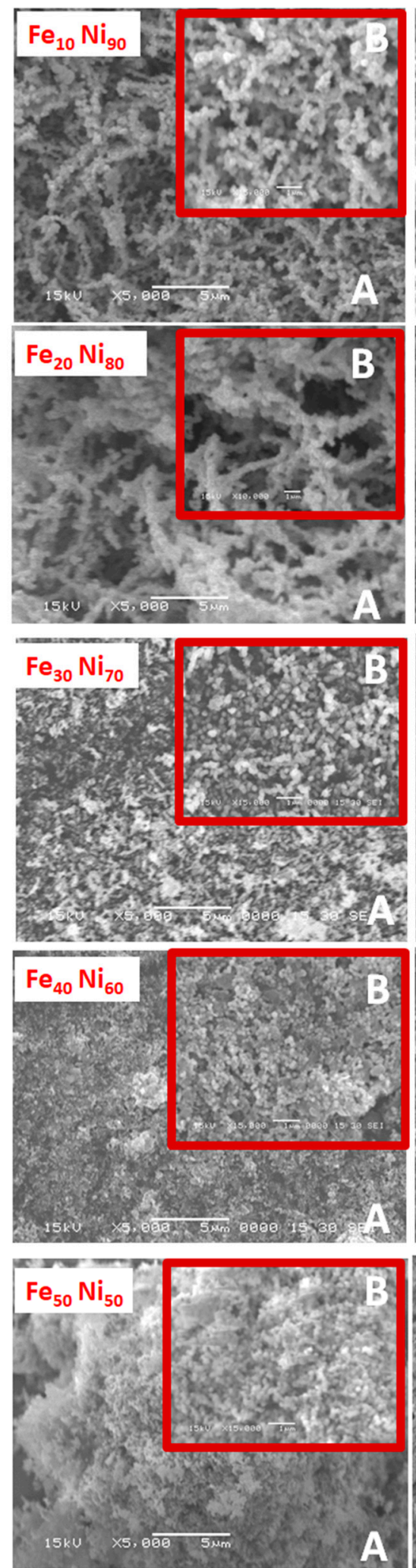

$0.1 \mathrm{M} 80 \mathrm{ml}$
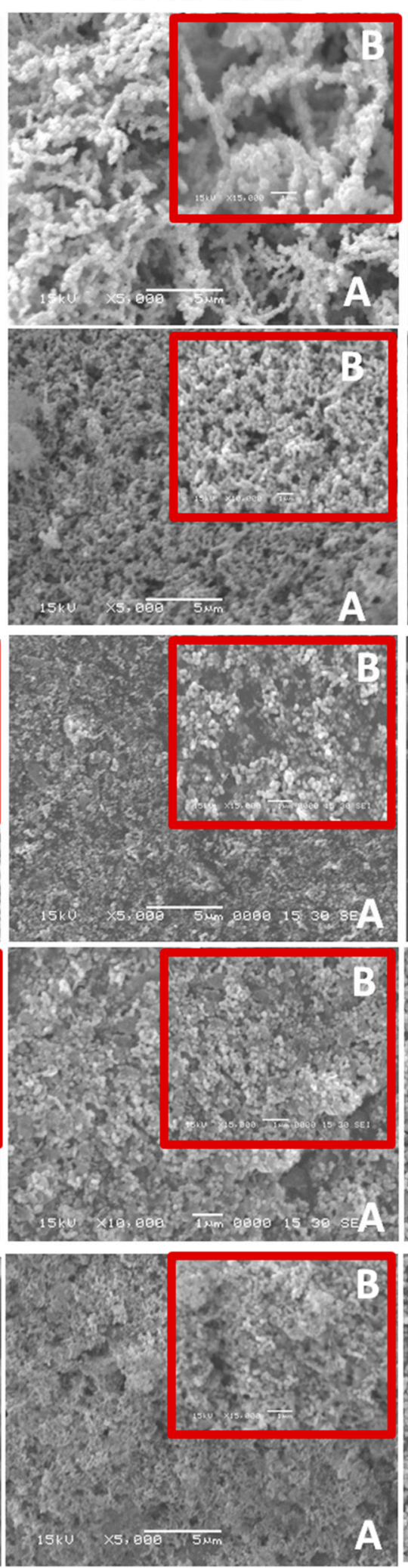

$0.3 \mathrm{M} 80 \mathrm{ml}$
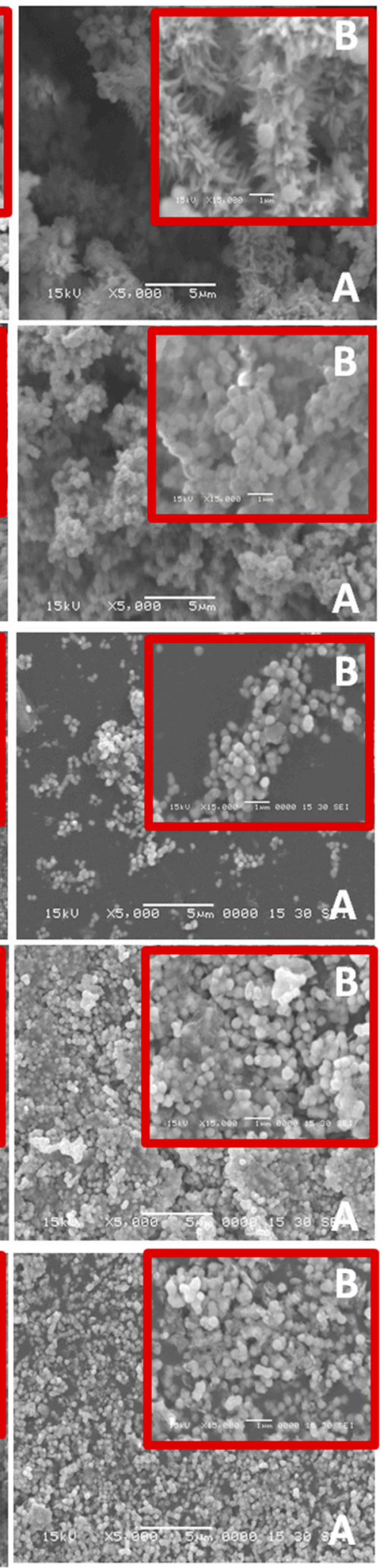

Figure 2. SEM images of the prepared iron-nickel alloy at two magnifications; (A) $\times 5000$ and $(\mathbf{B}) \times 15,000$. 


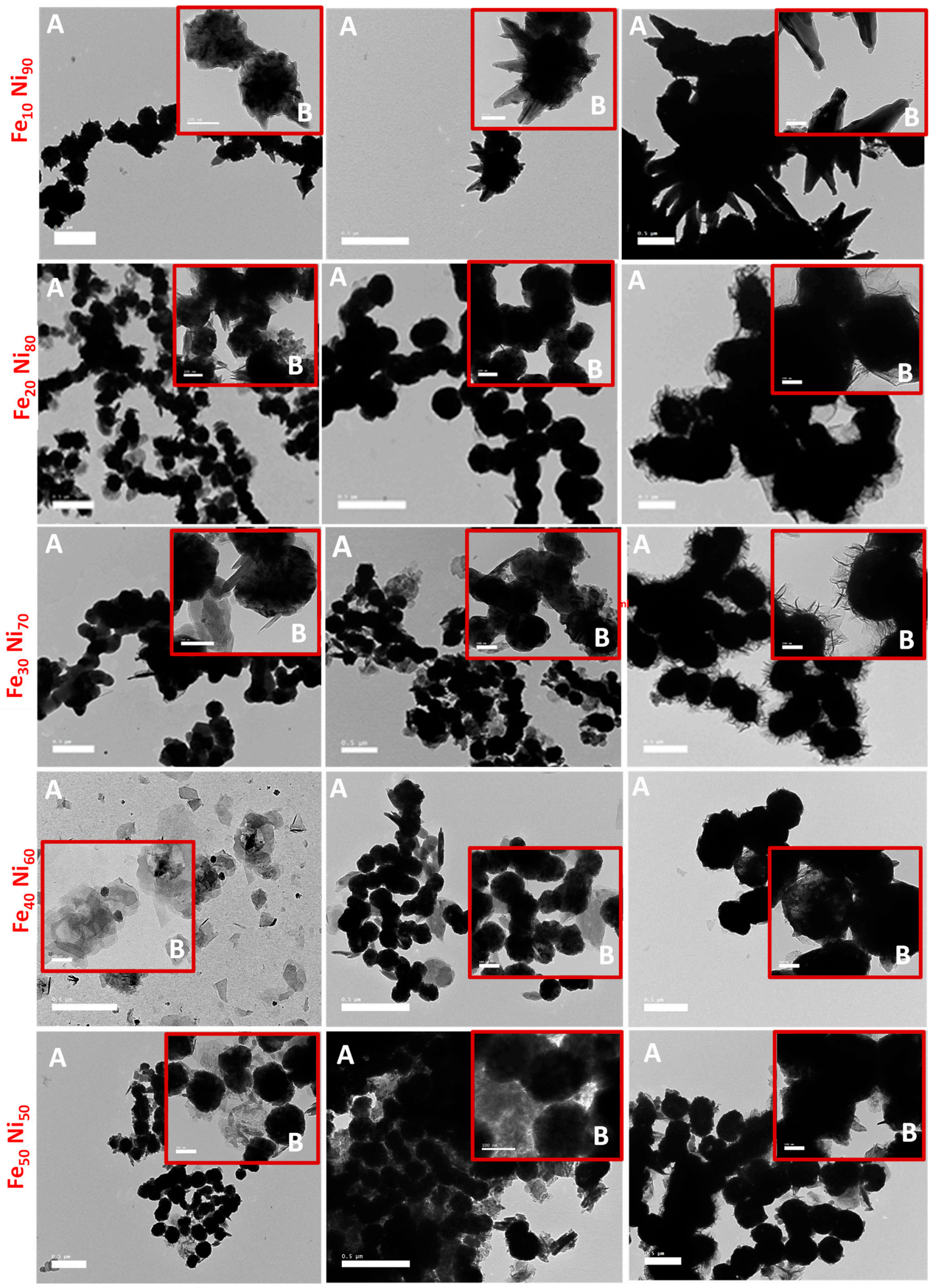

Figure 3. TEM images of the prepared iron-nickel alloy at two magnifications; $(\mathbf{A}) \times 5000$ and $(\mathbf{B}) \times 15,000$. 
This starfish diminished with an increase in the iron content to $\mathrm{Fe}_{20} \mathrm{Ni}_{80}$ molar ratio; however, a few cones/needles showed with small reaction volume $(0.1 \mathrm{M}$ with $40 \mathrm{~mL}$ reaction volume). Doubling the reaction volume and/or tripling the metal concentration resulted in replacing the cones/needles with hair around the formed necklace-like nanostructured alloy, especially with high metal concentration ( $0.3 \mathrm{M}$ metal concentration with $80 \mathrm{~mL}$ reaction volume) as shown in TEM images (Figure 3). Increasing the molar ratio to $\mathrm{Fe}_{30} \mathrm{Ni}_{70}$ also resulted in the necklace structure, but some clearer particles became predominate in the imaged alloy. Higher molar ratios (i.e., $\mathrm{Fe}_{40} \mathrm{Ni}_{60}$ and $\mathrm{Fe}_{50} \mathrm{Ni}_{50}$ ) resulted in diminishing the necklace-like nanostructured and formation of particle clusters, which may be attributed to the increase in the percentage of multi-domain particles.

The high-resolution TEM image shown in Figure 4 of the selected area in the sides cones shows a good crystalline character with a lattice spacing of $0.207 \mathrm{~nm}$; this can be indexed to the (111) plane of face-centered cubic FeNi nanocrystals, which suggested the cones grow along the (111) direction in which the magnetic particles grow along the magnetic easy axis of (111) direction.

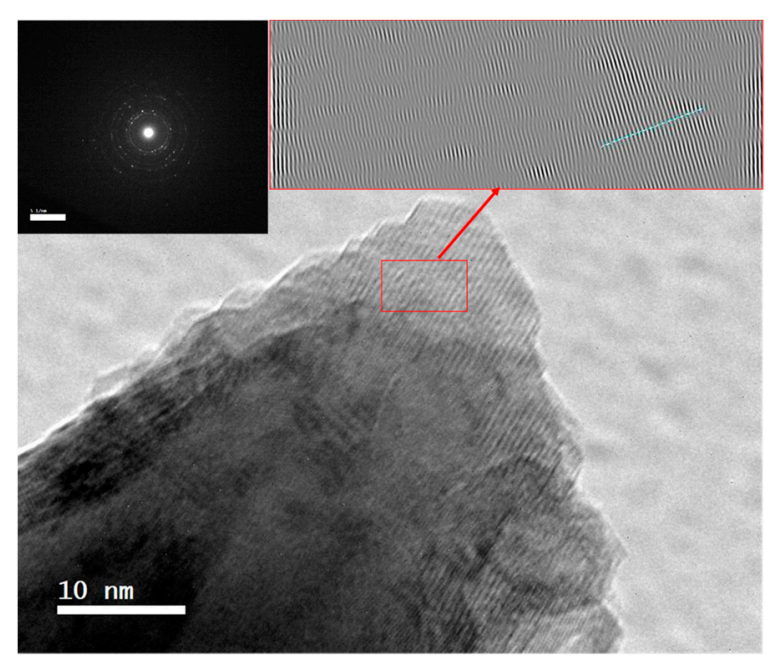

Figure 4. The high resolution TEM images of $\mathrm{Fe}_{10} \mathrm{Ni}_{90}$ molar ratio synthesized using $0.1 \mathrm{M}$ metal concentration and $80 \mathrm{~mL}$ reaction volume carried out for $15 \mathrm{~min}$ at $1400 \mathrm{rpm}$ and $95-98^{\circ} \mathrm{C}$.

\subsection{Alloy Particle Size}

The particle size of the syntheses' alloys was calculated using ImageJ software for SEM and TEM images and the obtained results are presented in Figure 5. The starfish-like shape image has a size of $211 \pm 42 \mathrm{~nm}$ for $0.1 \mathrm{M}$ metal concentration with $40 \mathrm{~mL}$ reaction volume. The average size of the alloy increased by around $80 \%$ to $379 \pm 50 \mathrm{~nm}$ with doubling the volume of the reaction solution $(0.1 \mathrm{M}$ metal concentration with $80 \mathrm{~mL}$ reaction volume). Also, an increase of around 152\% occurred with the metal concentration being increased threefold ( $0.3 \mathrm{M}$ metal concentration with $80 \mathrm{~mL}$ reaction volume) to reach $532 \pm 53 \mathrm{~nm}$. The images were also interpreted and confirmed by calculating the particle size through ImageJ software for the images of TEM. The TEM images illustrated that the reason for this growth of the particle size with an increase in either the reaction volume and/or metal concentration is due to the growth of the cones/needles in length by approximately 220 and $328 \%$ longitudinally and almost by 42 and 212\% crosswise with doubling the reaction volume and tripling the total metal concentration, respectively. The effect of cones/needles on the measured particle size increased by around 20\% (211 and $169 \mathrm{~nm}$ particle size with and without cones/needles, respectively) for $0.3 \mathrm{M}$ metal concentration with $80 \mathrm{~mL}$ reaction volume to around $50 \%$ by doubling the reaction volume ( 379 and $246 \mathrm{~nm}$ particle size with and without cones/needles, respectively) or/and tripling the total metal concentration (532 and $300 \mathrm{~nm}$ particle size with and without cones/needles, respectively). 


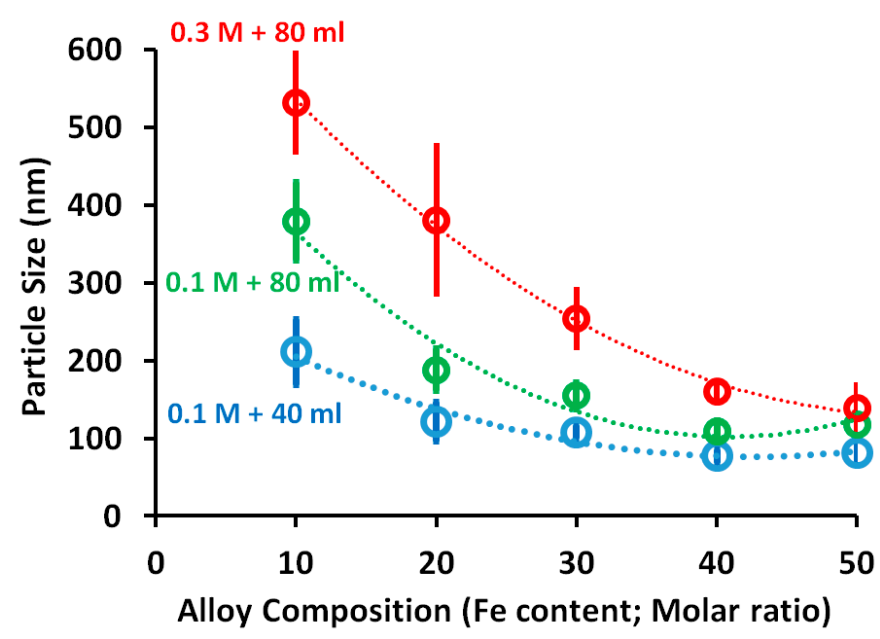

Figure 5. Particle size as function of the molar ratio of iron using ImageJ software; $40 \mathrm{~mL}$ reaction volume (blue circle) and $80 \mathrm{~mL}$ reaction volume (green circle) with $0.1 \mathrm{M}$ metal concentration, $80 \mathrm{~mL}$ reaction volume with $0.3 \mathrm{M}$ concentration (red circle).

On the other hand, the calculated particle size decreased with increases in the iron molar ratio, which can be related to changing the particle shapes from starfish-like through the necklace-like structures to clear particles. However, a few cones/needles showed with small reaction volume $(0.1 \mathrm{M}$ with $40 \mathrm{~mL}$ reaction volume) at $20 \%$ iron molar ratio $\left(\mathrm{Fe}_{20} \mathrm{Ni}_{80}\right)$ resulted in an increase in the gap between the calculated sizes, which increase the standard deviation as shown in Figure 4 at this point. In general, the effect of an increase in the total metal concentration on the particle size of the alloys is more visible than the effect of doubling the reaction volume at the same total metal concentration $(0.1 \mathrm{M})$.

\subsection{Alloy Composition}

Keeping in mind that EDX is not a tool for precision chemical analysis, (it is just an instrument for estimation of elements distribution in a specimen), the EDX analysis is a clear indication of the surface degradation due to oxide layer formation covering the synthesized alloys. The oxidation is inevitable in ferromagnetic nanoparticles, and they can influence the magnetic properties of the alloys in which $\mathrm{Ni}_{2} \mathrm{O}_{3}$ is weakly magnetic; $\mathrm{NiO}$ is antiferromagnetic, $\mathrm{Ni}(\mathrm{OH})_{2}$ is nonmagnetic whereas $\mathrm{Fe}_{2} \mathrm{O}_{3}$ is ferromagnetic [45].

As shown in Table 1, the alloys with $\mathrm{Fe}_{10} \mathrm{Ni}_{90}, \mathrm{Fe}_{20} \mathrm{Ni}_{80}$, and $\mathrm{Fe}_{30} \mathrm{Ni}_{70}$ molar ratio possess high purity with minimal oxides forming, as confirmed by both TEM and SEM instruments with differences in the X-ray source, and its depth of penetration (i.e., In SEM, the source of X-rays is a sphere with a diameter of about $1000 \mathrm{~nm}$, whereas, in TEM, the source of X-rays is a disk with beam's diameter and a thin (50-100 nm) section). The increase in the iron content (molar ratio) to more than 30\% resulted in an increase in the oxygen content of the synthesized alloy; for that, the alloy purity significantly decreased with a higher molar ratio than $\mathrm{Fe}_{30} \mathrm{Ni}_{70}$ (especially alloy $\mathrm{Fe}_{50} \mathrm{Ni}_{50}$ molar ratio). Indeed, the $\mathrm{Fe}_{10} \mathrm{Ni}_{90}$ molar ratio alloy is very pure without oxides forms as supported by a full agreement between EDX analyses using both SEM and TEM with their difference the $\mathrm{X}$-ray sources and penetration. The EDX analysis of the synthesized $\mathrm{Fe}_{10} \mathrm{Ni}_{90}$ alloy using both SEM and TEM, as well as the TEM mapping of its composition, shown in Figure 6. 
Table 1. EDX analysis of the synthesized five alloys equipped with TEM and SEM. Reaction reference: $0.1 \mathrm{M}$ metal concentration, $80 \mathrm{~mL}$ reaction volume, $1400 \mathrm{rpm}$, and $95-98^{\circ} \mathrm{C}$.

\begin{tabular}{|c|c|c|c|c|c|c|c|c|c|c|c|c|}
\hline \multirow{3}{*}{$\begin{array}{l}\text { Iron: Nickel } \\
\text { Molar Ratio }\end{array}$} & \multicolumn{6}{|c|}{ TEM EDX Analysis } & \multicolumn{6}{|c|}{ SEM EDX Analysis } \\
\hline & \multicolumn{3}{|c|}{ Atomic \% } & \multicolumn{3}{|c|}{ Mass \% } & \multicolumn{3}{|c|}{ Atomic \% } & \multicolumn{3}{|c|}{ Mass \% } \\
\hline & $\mathbf{F e}$ & $\mathrm{Ni}$ & $\mathbf{O}$ & $\mathbf{F e}$ & $\mathrm{Ni}$ & $\mathbf{O}$ & $\mathrm{Fe}$ & $\mathrm{Ni}$ & $\mathbf{O}$ & $\mathbf{F e}$ & $\mathrm{Ni}$ & $\mathbf{O}$ \\
\hline $10: 90$ & 11.36 & 88.64 & 0.00 & 10.87 & 89.13 & 0.00 & 10.74 & 89.22 & 0.05 & 10.27 & 89.72 & 0.01 \\
\hline $20: 80$ & 17.50 & 71.71 & 10.78 & 18.24 & 78.54 & 3.22 & 20.05 & 79.05 & 0.89 & 19.39 & 80.36 & 0.25 \\
\hline $30: 70$ & 28.51 & 62.44 & 9.06 & 29.47 & 67.85 & 2.68 & 31.25 & 67.22 & 1.53 & 30.53 & 69.04 & 0.43 \\
\hline $40: 60$ & 34.88 & 47.76 & 17.36 & 38.73 & 55.75 & 5.52 & 39.89 & 56.60 & 3.51 & 39.20 & 58.27 & 2.53 \\
\hline $50: 50$ & 39.06 & 40.19 & 20.74 & 44.77 & 48.42 & 6.81 & 41.92 & 42.82 & 15.26 & 45.91 & 49.30 & 4.79 \\
\hline
\end{tabular}

(A)

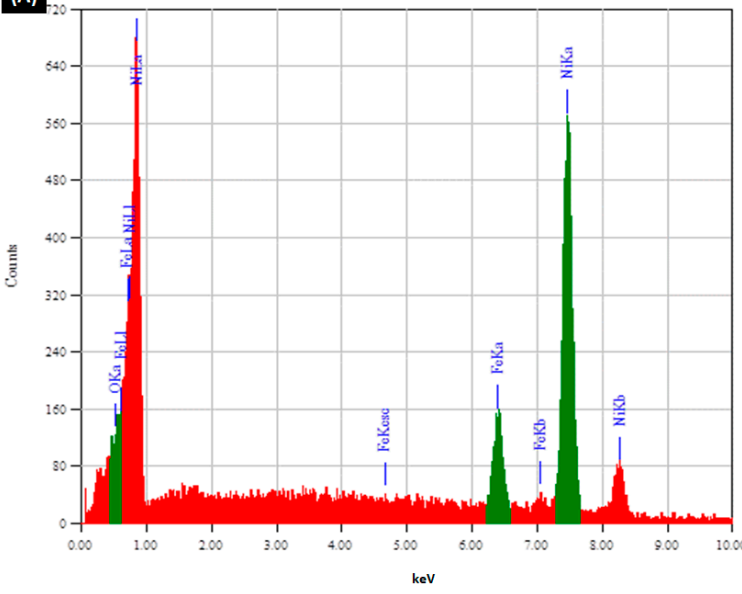

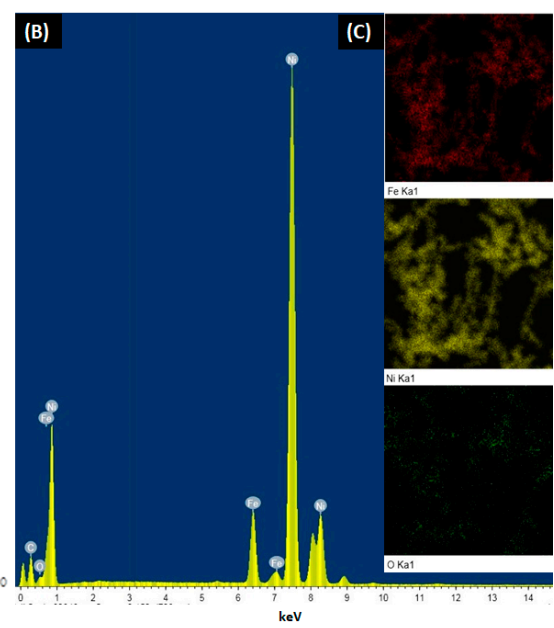

Figure 6. EDX analysis of the synthesized $\mathrm{Fe}_{10} \mathrm{Ni}_{90}$ alloy using (A) SEM and (B) TEM. (C) TEM mapping of the alloy. Reaction reference: $0.1 \mathrm{M}$ metal concentration, $80 \mathrm{~mL}$ reaction volume, $1400 \mathrm{rpm}$, and $95-98^{\circ} \mathrm{C}$.

In full support of the obtained EDX results, the XRD pattern of the different alloys is shown in Figure 7. From the literature, the diffraction peaks correspond (111), (200), and (220) reflections of $\gamma$-nickel with face-centered cubic structure (fcc). The synthesized alloys in full agreement with the face-centered cubic (fcc) nickel crystal (JCPDS Card No. 04-0850), and the peaks located at $44.41^{\circ}, 51.71^{\circ}$, and $76.21^{\circ}$ can be indexed to (111), (200), and (220) planes of the crystalline face-centered cubic (fcc) FeNi 3 alloy (JCPDS 65-3244). This proved that $\mathrm{Ni}^{2+}$ and $\mathrm{Fe}^{2+}$ salts were almost reduced to zerovalent metals and formed $\mathrm{FeNi}_{3}$ alloy. The strong and sharp peaks and very low backgrounds revealed that $\gamma$-Ni particles had a high degree of crystallization and no characteristic peaks due to impurities of nickel or iron oxides and hydroxides, which indicates pure alloy formation especially with the iron molar ratio 10,20 , and $30 \%\left(\mathrm{Fe}_{10} \mathrm{Ni}_{90}, \mathrm{Fe}_{20} \mathrm{Ni}_{80}\right.$, and $\left.\mathrm{Fe}_{30} \mathrm{Ni}_{70}\right)$. The XRD peaks of hexagonal plates can be indexed as hexagonal $\mathrm{Ni}(\mathrm{OH})_{2}$ (JCPDS Card No. 14-0117) and fcc nickel. The broad $\mathrm{Ni}(\mathrm{OH})_{2}$ diffraction peaks such as (001) show a poorly crystallized layered phase with a turbostratic disorder for the presence of $\mathrm{Cl}^{-}$in the case of nickel chloride, which was used as the nickel source [16], and appeared at an iron molar ratio higher than $30 \%$ as shown in Figure 7A for $\mathrm{Fe}_{40} \mathrm{Ni}_{60}$ and $\mathrm{Fe}_{50} \mathrm{Ni}_{50}$ molar ratios. The good purity of the three first iron molar ratios $\left(\mathrm{Fe}_{10} \mathrm{Ni}_{90}, \mathrm{Fe}_{20} \mathrm{Ni}_{80}\right.$, and $\mathrm{Fe}_{30} \mathrm{Ni} 70$ ) does not change with tripling the metal concentration as shown in Figure 7B. In other words; X-ray diffraction presented a complete phase purity for the alloys synthesized in this work using an iron molar ratio not exceeding $30 \%$. 

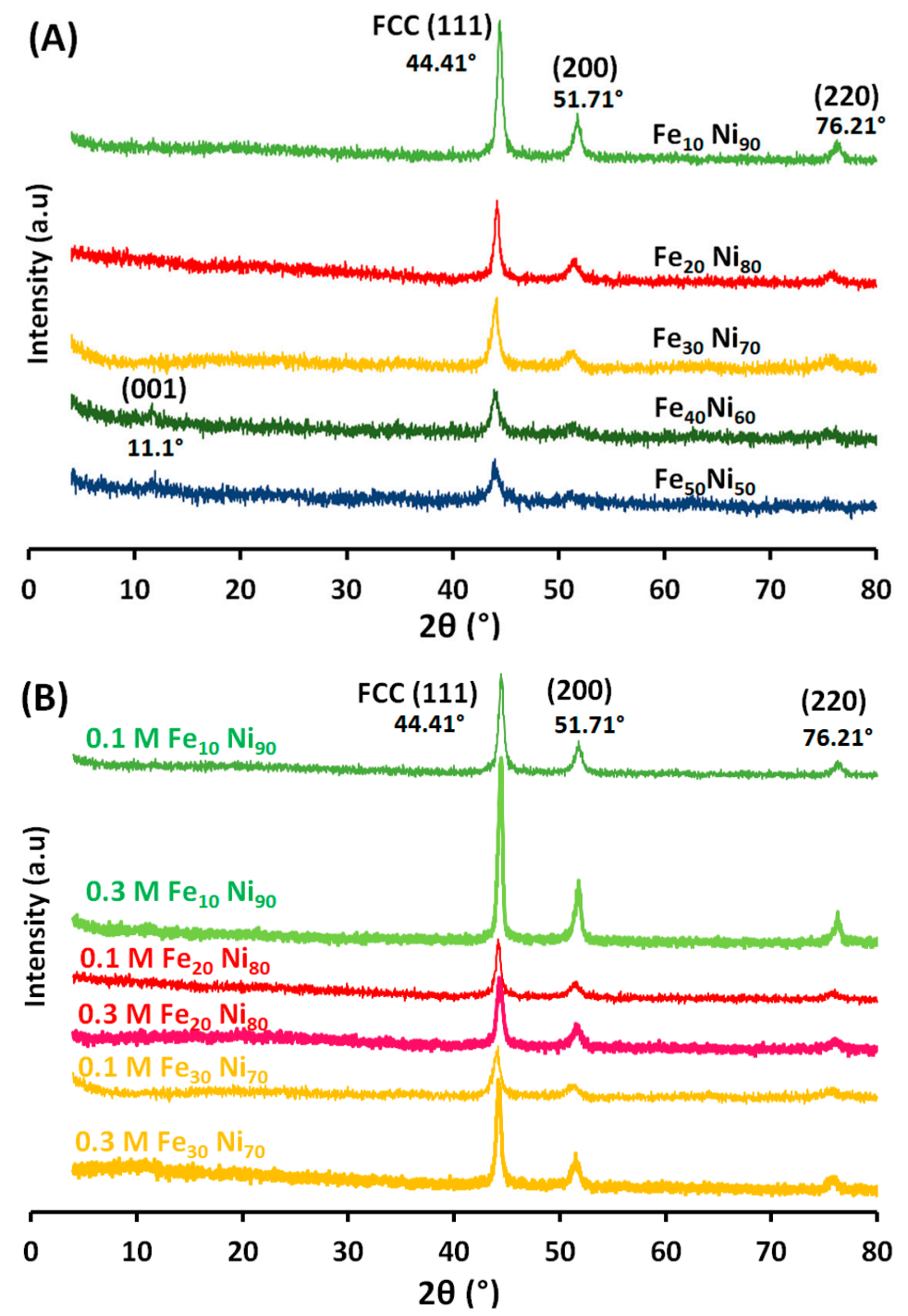

Figure 7. XRD pattern of the prepared iron-nickel alloys using (A) different iron-nickel molar ratio with $0.1 \mathrm{M}$ metal concentration and $80 \mathrm{~mL}$ reaction volume, (B) 10 to $30 \%$ iron molar ratio at both 0.1 and $0.3 \mathrm{M}$ metal concentration and $80 \mathrm{~mL}$ reaction volume. Reference condition: $1400 \mathrm{rpm}$, and $95-98^{\circ} \mathrm{C}$.

The average crystallite sizes of the iron-nickel alloys synthesized at various molar ratios were calculated based on the full width at half maximum of the (111) peak in the corresponding XRD patterns, using the Scherrer formula [46]. The data range from 15.88 to $7.93 \mathrm{~nm}$ corresponding to $\mathrm{Fe}_{10} \mathrm{Ni}_{90}$ to $\mathrm{Fe}_{50} \mathrm{Ni}_{50}$, respectively, indicating that all the synthesized iron-nickel alloys are nanostructured, regardless of the synthesis conditions.

As shown in Figure 8, the lattice parameter of the fcc FeNi alloys is filling between the lattice parameters of pure fcc nickel (3.52 $\AA$ ) and pure fcc iron (3.59 $\AA$ ). As noticed, the lattice parameter of the $\mathrm{Fe}_{10} \mathrm{Ni}_{90}$ alloy is closer to that of pure nickel spectra as the prepared alloy is rich in nickel atoms. This can be related to the molar ratio of $\mathrm{Fe}^{2+}$ to $\mathrm{Ni}^{2+}$ that is equal or near to $1 / 3 ; \mathrm{Ni}^{2+}$ and $\mathrm{Fe}^{2+}$ were completely reduced into $\mathrm{Fe}$ and $\mathrm{Ni}$, resulting in the formation of (FCC) $\mathrm{FeNi}_{3}$ phase [47-49]. The increase in the iron molar ratio to $\mathrm{Fe}_{20} \mathrm{Ni}_{80}$ and $\mathrm{Fe}_{30} \mathrm{Ni}_{70}$ resulted in shifting the lattice parameter toward the pure iron that indicated iron consolidation into the lattice of nickel in which the ionic radius of iron is different than that of nickel. 


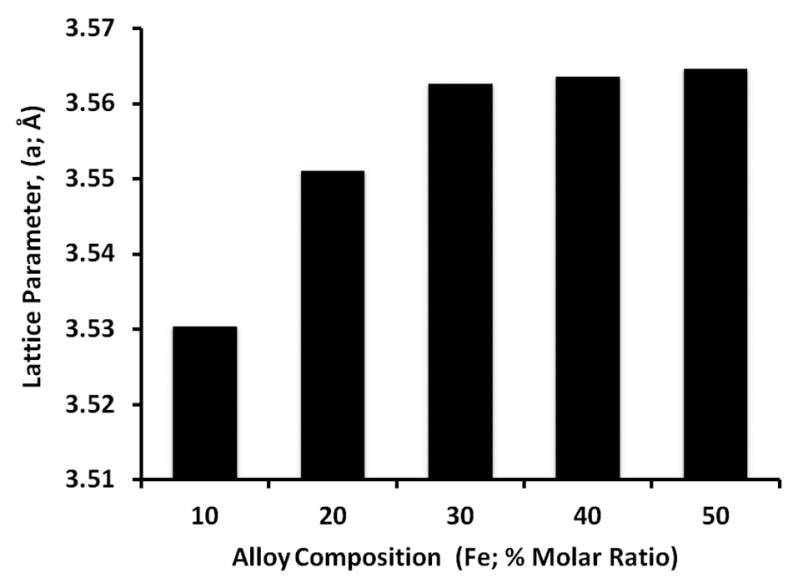

Figure 8. The lattice parameter as function of alloy composition ( $\%$ Fe molar ratio).

Figure 8 does not agree with Vegard's law [50] for iron molar ratio higher than $30 \%$, according to which the crystal lattice parameter of the alloys should increase linearly with an increase in the concentration of larger iron atoms. A deviation from Vegard's law occurs in case of $x=10-30$, the solid solution is ordered to form the $\mathrm{FeNi}_{3}$ phase, whose parameter $\mathrm{a}=3.55 \AA$ (JCPDS Card No. 01-077-7971). An increase in the lattice parameter for the alloy at $x>30$, and a slowdown in the growth for $x=40$ or 50 may be due to the conditions of the stoichiometry of the superstructure phase of $\mathrm{FeNi}_{3}$ and the presence of defects in it, as well as the dimensional effects of nanocrystals.

\subsection{Alloy Reaction Mechanism}

The reaction progress in the current route could be expressed as the following equations:

$$
\begin{aligned}
& 2 \mathrm{~N}_{2} \mathrm{H}_{4}+8 \mathrm{OH}^{-} \leftrightarrow 2 \mathrm{~N}_{2}+8 \mathrm{H}_{2} \mathrm{O}+8 \mathrm{e}^{-} \\
& 2 \mathrm{Fe}^{2+}+\mathrm{N}_{2} \mathrm{H}_{4}+4 \mathrm{OH}^{-} \rightarrow 2 \mathrm{Fe}+\mathrm{N}_{2}+4 \mathrm{H}_{2} \mathrm{O} \\
& 2 \mathrm{Ni}^{2+}+\mathrm{N}_{2} \mathrm{H}_{4}+4 \mathrm{OH}^{-} \rightarrow 2 \mathrm{Ni}+\mathrm{N}_{2}+4 \mathrm{H}_{2} \mathrm{O} \\
& \mathrm{Fe}^{2+}+\mathrm{Ni}^{2+}+4 \mathrm{e}^{-} \rightarrow \mathrm{FeNi} \\
& \mathrm{Fe}+3 \mathrm{Ni} \rightarrow \mathrm{FeNi}_{3}
\end{aligned}
$$

When $\mathrm{Fe}(\mathrm{III})$ and $\mathrm{Ni}(\mathrm{II})$ are treated with alkaline hydrazine hydrate, it resulted in $\mathrm{Fe}(\mathrm{OH})_{3}$, which is easily formed. $\mathrm{Ni}(\mathrm{II})$ is readily reduced to Ni particles for cooperation with hydrazine hydrate, which in turn reduces $\mathrm{Fe}(\mathrm{OH})_{3}$ to Fe particles. In case of equal or near the 1:3 molar ratio of $\mathrm{Fe}^{3+}$ to $\mathrm{Ni}^{2+}$ ions, both $\mathrm{Fe}^{3+}$ and $\mathrm{Ni}^{2+}$ can be completely reduced into $\mathrm{Fe}$ and $\mathrm{Ni}$, resulting in the formation of fcc $\mathrm{FeNi}_{3}$ phase with $\mathrm{AuCu}_{3}$ type structure. Based on a precipitate slow-release process, $\mathrm{Fe}^{3+}$ and $\mathrm{Ni}^{2+}$ can be slowreleased from $\mathrm{Fe}(\mathrm{OH})_{3}$ and $\mathrm{Ni}(\mathrm{OH})_{2}$ by high-temperature decomposition, and consequently, the concentrations of $\mathrm{Fe}^{3+}$ and $\mathrm{Ni}^{2+}$ are kept at a 1:3 ratio level, which is in favor of anisotropic growth. Fractal growth is a nonequilibrium, diffusion-controlled kinetic process, which has been supported by the diffusion-limited aggregation (DLA) [51] or oriented aggregation mechanism [52].

\subsection{Thermal Properties}

In the DSC diagram shown in Figure 9, two endothermic peaks were identified. The first broad peak was around $97-154{ }^{\circ} \mathrm{C}$ and around $433-455^{\circ} \mathrm{C}$, respectively. The endothermic peak at $97-154^{\circ} \mathrm{C}$ can be attributed to water evaporation. This peak is pronounced for alloys with $\mathrm{Fe}_{30} \mathrm{Ni}_{70}, \mathrm{Fe}_{40} \mathrm{Ni}_{60}$, and $\mathrm{Fe}_{50} \mathrm{Ni}_{50}$ molar ratios. Clearly, this peak does not exist in $\mathrm{Fe}_{10} \mathrm{Ni}_{90}$ and $\mathrm{Fe}_{20} \mathrm{Ni}_{80}$ alloys. The second endothermic peak around $433-455{ }^{\circ} \mathrm{C}$ can be attributed to the Curie transition temperature (i.e., the Curie temperature is the temperature above which magnetic materials lose their ferromagnetic properties, to be 
replaced by paramagnetism). The Curie transition temperature of nanoparticles is lower than that of the bulk, which occurs at temperatures close to $580^{\circ} \mathrm{C}$ [29]. The decrease in the particle size leads to a decrease in the overall ordering of the magnetic phase, which can be related to both fractions of the atoms on a disordered surface being less tightly subjected to a super-exchange interaction and less ordered crystal structure in comparison to the grain interior [47]. The broad endothermic peak occurs dependent on the crystallite sizes, where the transition takes place from the pc (i.e., The primitive cubic system $(\mathrm{cP})$ consists of one lattice point on each corner of the cube). The (111) plane of a face-centered cubic system is a hexagonal grid. On the other hand, the remarkable exothermic peak at $285{ }^{\circ} \mathrm{C}$ was observed, which can be attributed to crystallization, in which a grain-size increase would accompany a crystallization process.

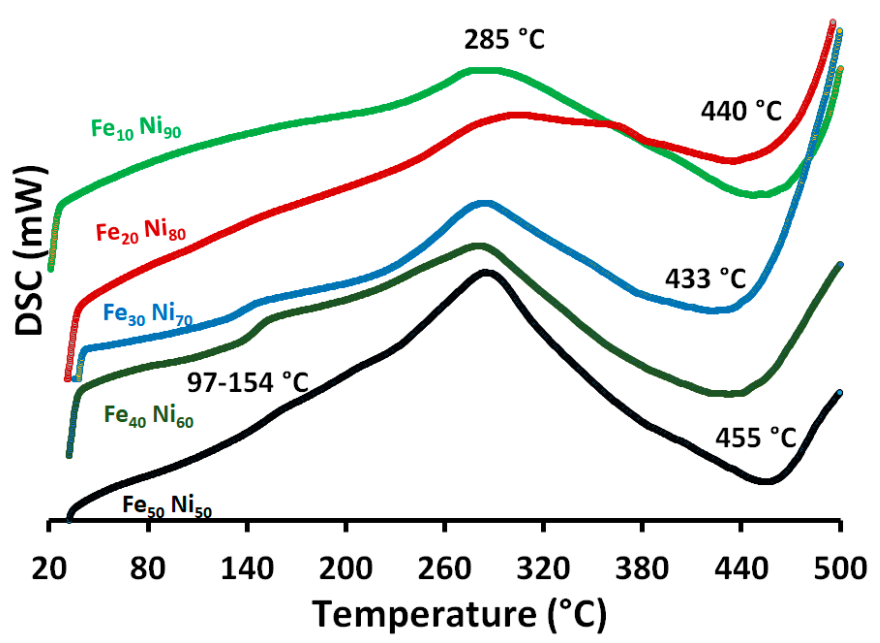

Figure 9. The DSC diagram of the prepared iron-nickel alloys using different iron-nickel molar ratio (10-50\% Fe). Reaction reference: $0.1 \mathrm{M}$ metal concentration, $80 \mathrm{~mL}$ reaction volume, $1400 \mathrm{rpm}$, and $95-98^{\circ} \mathrm{C}$.

\subsection{Magnetic Properties}

Figure 10 shows the hysteresis loop of synthesized iron-nickel $\left(\mathrm{FeNi}_{3}\right)$ alloy. It indicates that the sample has the symmetric hysteresis loop behavior of ferromagnetic materials. The presented iron-nickel in this work shows a wide range of superior magnetic properties that can be tailored to the need of certain requirements by adjusting the chemical composition. The highest coercivity without significant reduction in saturation magnetization reveals that the magnetic behavior of $\mathrm{Fe}_{10} \mathrm{Ni}_{90}$ alloy surpasses that of soft ones.

The larger coercivity of the $\mathrm{FeNi}_{3}$ starfish-like structure in $\mathrm{Fe}_{10} \mathrm{Ni}_{90}$ alloy could be attributed to the intrinsic large magnetocrystalline anisotropy of ordered intermetallic compared with the disordered $\mathrm{FeNi}_{3}$ permalloy. Also, the effect of size, shape, and structure compared with the $\mathrm{FeNi}_{3}$ necklace-like or particles of other synthesized alloys. Indeed, other parameters such as composition, internal stress, and defects also influence alloy magnetic properties. The magnetic properties of $\mathrm{FeNi}_{3}$ structures may be explained depending on crystalline and shape anisotropy, which needs to be studied further.

For a clear study of the magnetic properties; coercivity, magnetization, receptivity, and squareness were drawn as functions of the iron molar ratio, as shown in Figure 11. The $\mathrm{Fe}_{10} \mathrm{Ni}_{90}$ alloy shows a high coercivity of 115.06 Oe in the case of $40 \mathrm{~mL}$ reaction volume, which improved to 118.55 Oe with doubling the reaction volume $(80 \mathrm{~mL})$. These values slightly decreased with increasing the iron content in the alloy up to $\mathrm{Fe}_{30} \mathrm{Ni}_{70}$ alloy (77.24 and 102.53 Oe for 40 and $80 \mathrm{~mL}$ reaction volume, respectively). 

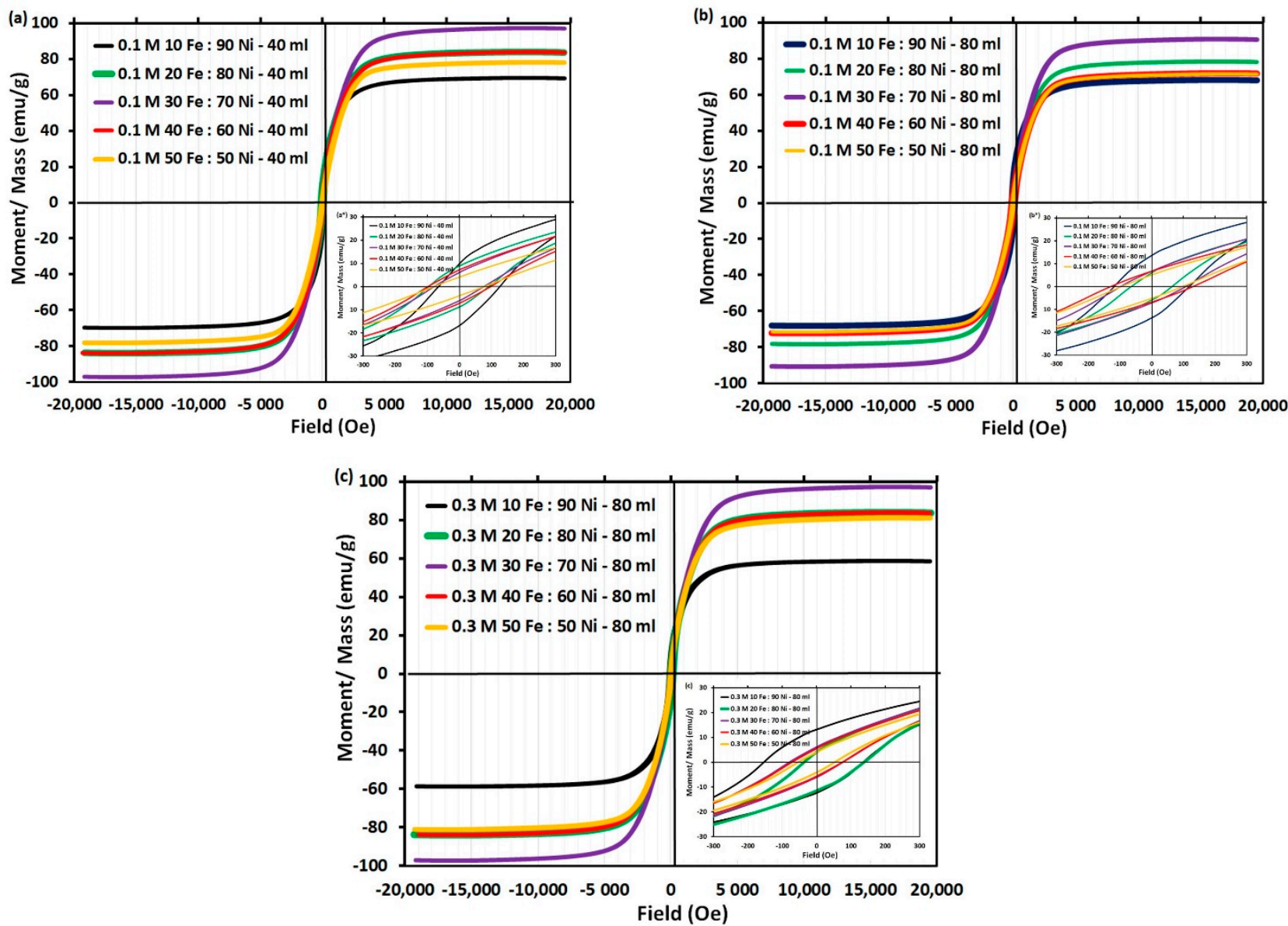

Figure 10. The M-H hysteresis loops of the iron-nickel microcrystals at room temperature; (a) $0.1 \mathrm{M}$ metal concentration in $40 \mathrm{~mL}$ reaction volume, (b) $0.1 \mathrm{M}$ metal concentration in $80 \mathrm{~mL}$ reaction volume, and (c) $0.3 \mathrm{M}$ metal concentration in $80 \mathrm{~mL}$ reaction solution. Reaction reference: $1400 \mathrm{rpm}$ and $95-98^{\circ} \mathrm{C}$.

Although we observed increases in the coercivity by doubling the reaction volume for all studied iron molar ratios except $\mathrm{Fe}_{50} \mathrm{Ni}_{50}$ alloy, an increase in the metal concentration from 0.1 (Curves 1 and 2; Figure 11) to $0.3 \mathrm{M}$ (Curve 3; Figure 11) resulted in a clear significant reduction in the coercivity of all synthesized alloys. However, $\mathrm{Fe}_{10} \mathrm{Ni}_{90}$ alloy kept a minimum reduction in its coercivity by tripling the total metal concentration. Conversely, the same saturation magnetization (Ms) $\left(68.7\right.$ and $68.2 \mathrm{emu} \mathrm{g}^{-1}$ for 40 and $80 \mathrm{~mL}$ reaction volume, respectively) is observed for the $\mathrm{Fe}_{10} \mathrm{Ni}_{90}$ alloy. The $\mathrm{Ms}$ increased with an increase in the iron content in the alloy up to $30 \%\left(97.2\right.$ and $90.9 \mathrm{emu} \cdot \mathrm{g}^{-1}$ for 40 and $80 \mathrm{~mL}$ resection volume, respectively). The increase in Ms with an increase in the iron content of the alloy is due to the high inherent magnetization of iron [48]. The increased magnetization could be established by the Slater-Pauling curve [49,53]. In full agreement with previous work [54], increasing iron concentration in the alloy results in an increase in Ms whereas Hc decreases proportionally. The highest Retentivity (Mr) and Squareness were recorded for $\mathrm{Fe}_{10} \mathrm{Ni}_{90}$ alloy that decreased with increases the iron molar ratio. More pronounced is the nearly stable, high magnetic properties of the $\mathrm{Fe}_{10} \mathrm{Ni}_{90}$ alloy with different reaction conditions (i.e., doubling the reaction volume and/or tripling the total metal concentration). 

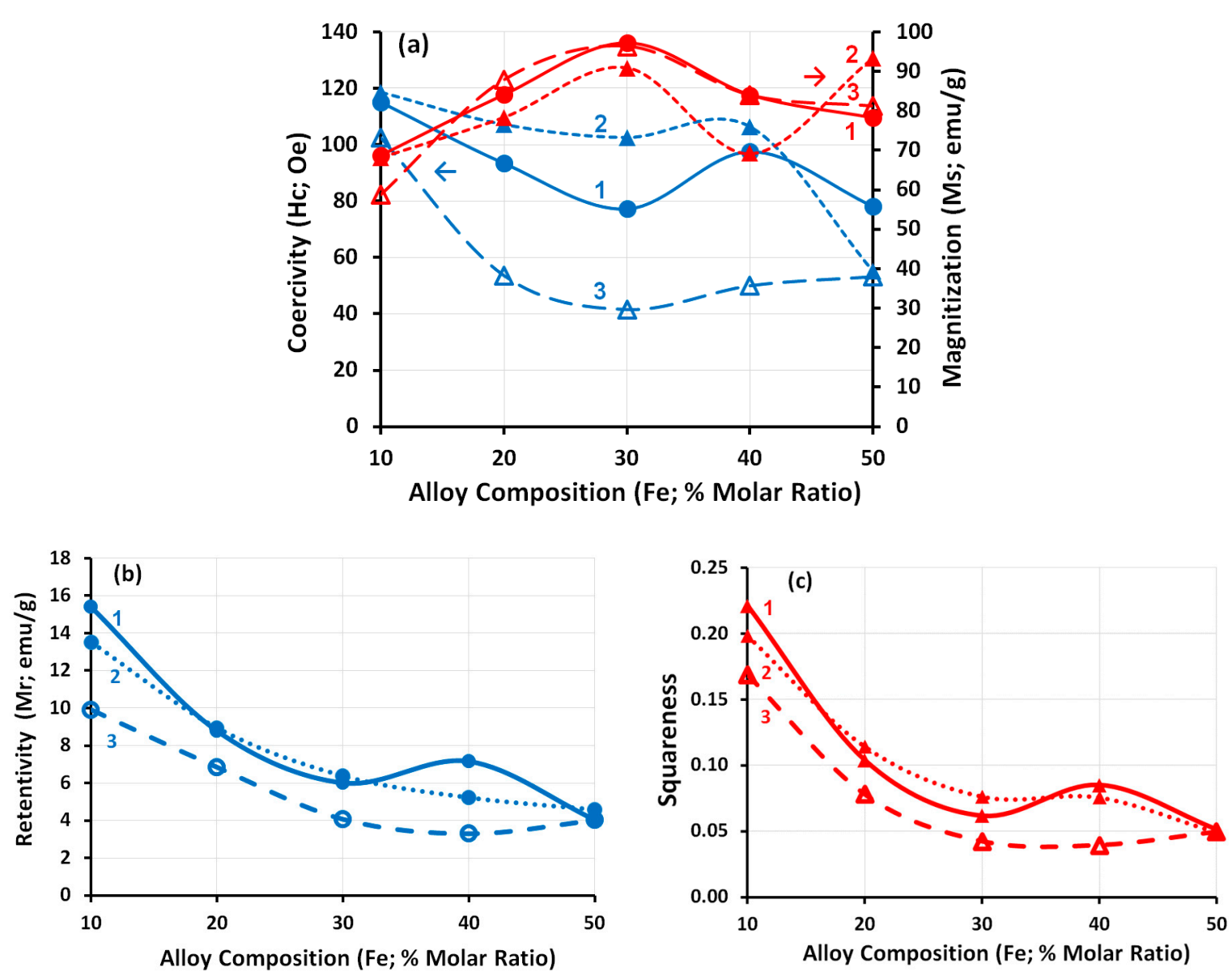

Figure 11. Magnetic Properties as function of Iron molar ratio in the alloys; (a) Coercivity and Magnetization, (b) Retentivity, and (c) Squareness. Reference conditions: Curve 1: $0.1 \mathrm{M}$ metal concentration in $40 \mathrm{~mL}$ reaction volume, Curve 2: $0.1 \mathrm{M}$ metal concentration in $80 \mathrm{~mL}$ reaction volume, and Curve 3: $0.3 \mathrm{M}$ metal concentration in $80 \mathrm{~mL}$ reaction solution.

\section{General Discussion}

Although it is possible to prepare the nanostructured alloy from iron and nickel in different ways, most of these methods suffer from problems that may reduce the purity of the resulting alloy and affect its magnetic properties. These problems emerge due to the following reasons: (1) the use of an expensive equipment such as autoclave, or special preparation capabilities and conditions such as the reflux process, (2) the use of auxiliaries as surfactants, templates or organic solvents, whether for preparation or washing, which negatively affect the purity of the alloy and increase its manufacture costs, (3) the preparation time is long, up to $10 \mathrm{~h}$, in addition to the drying time, (4) the magnetic properties are low to medium in relation to the cost, conditions and quality of the devices used for preparation, (5) the scarcity of the alloy composition of iron and nickel rich in nickel $\left(\mathrm{Fe}_{10} \mathrm{Ni}_{90}\right)$ and the low purity of the prepared alloys, (6) there are no sufficient studies to prepare high magnetic properties of $\mathrm{Fe}_{10} \mathrm{Ni}_{90}$ using simple, inexpensive and easy-to-control methods such as simple chemical reduction, and (7) there are no studies documenting the study of the effect of the volume of the reaction solution on the purity and properties of iron and nickel alloys. All these defects have been overcome in this study.

Generally, the preferential growth direction of alloy particles follows the route of the minimum magnetic anisotropic energy and/or surface free energy. The ferromagnetic iron-nickel alloy has an fcc structure that possesses a lower surface energy value than (100) and (110). For that, the magnetic particles grow along the magnetic easy axis of (111) direction, and thus (111) consists of more facets. On other hand, fast grain growth leads to a similar growth rate of various facets and isotropic morphology, such as spheres, which are usually formed. Whereas, at low grain growth rate, the alloy particles have enough 
time to grow along the preferential direction. Hence, an anisotropic growth along the (111) direction occurs, driven by the minimization of magnetic anisotropic energy and surface free energy. From this point, the $\mathrm{OH}^{-}$ions play an important role in the reduction and particle growth in which it complexes the metal ions and acts as a capping agent. There are three cases depending on the molar ratio of free $\mathrm{OH}^{-} / \mathrm{M}^{+}$ions; the first case is if the molar ratio of free $\mathrm{OH}^{-} / \mathrm{M}^{+}$ions is high, in which $\mathrm{OH}^{-}$ions are enough to completely cap the growing particles. The opposite case is if the molar ratio of free $\mathrm{OH}^{-} / \mathrm{M}^{+}$ions is low in which $\mathrm{OH}^{-}$ions are not enough to cap any face of the growing particles. The previous two cases lead to isotropic particle growth. The third case is the medium molar ratio of free $\mathrm{OH}^{-} / \mathrm{M}^{+}$ions in which partially cap the growing particles and anisotropic particle growth along the preferential direction takes place [31]. However, in this work, the ratio of free $\mathrm{OH}^{-} /\left(\mathrm{Fe}^{2+}\right.$ and $\left.\mathrm{Ni}^{2+}\right)$ ions should not change as the reaction goes on because both types of ions are consumed according to the stoichiometric ratio. Accordingly, the effect of the ratio between $\mathrm{Fe}^{2+}$ and $\mathrm{Ni}^{2+}$ ions in the reaction medium is highlighted. By beginning with molar ratio $\mathrm{Fe}_{10} \mathrm{Ni}_{90}$, and the presence of excess nickel ions and hydrazine, and because the bond energy between $\mathrm{OH}^{-}$and nickel ions is larger than that between hydrazine and nickel ions, then it is apparent that the chemical bond between nickel ions and hydrazine is more likely to form before the reduction, which influences the growth rate of some crystal faces that result in the anisotropic growth; finally, the starfish-like shape morphology is formed. Moreover, the atomic percentage of oxygen in $\mathrm{Fe}_{10} \mathrm{Ni}_{90}$ alloy is up to $0.05 \%$, indicating that no oxide layer formed on the particle surface.

The strong and sharp peaks revealed that $\gamma$-Ni particles had a high degree of crystallization. The $\mathrm{FeNi}_{3}$ starfish-like nanostructured alloy is more stable; this proves that iron and nickel ions in the reaction solution are almost reduced to zerovalent metals and secure from further oxidation. With increasing the iron ions and decreases the nickel ions, a very slight shift in the XRD sharp single phase peak position is observed, indicating iron consolidation into the lattice of nickel due to the different ionic radius of iron. This implies that $\mathrm{Fe}$ atoms are incorporated into the fcc $\mathrm{Ni}$ lattice, leading to the enlargement of the interplanar spacing because the radius of $\mathrm{Fe}$ atoms $(1.26 \AA)$ is larger than that of $\mathrm{Ni}$ atoms $(1.24 \AA)$.

On the other hand, the lower possibility of bonding nickel and $\mathrm{OH}^{-}$ions makes the argument for strengthening $\mathrm{OH}^{-}$ions' role as capping agent and the growth of the three crystal planes $(100,110$ and 111) with an isotropic particle growth. The necklace-like nanostructured consists of several nanospheres, which are collected together and form the necklace-like shape that can be illustrated by a dipole-directed assembly mechanism [22] All dipoles could be located in a group of nanospheres, which resulted in a decrease in the magnetostatic energy and in the spontaneous magnetostatic field, and consequently resulted in the degradation of dipoles in the manner of interaction between the unpaired end dipoles of two or several nanoparticles/chains. Necklace-like nanostructured chains with the same magnetostatic direction are linked together by a second magnetostatic field that would induce self-assembly, and a necklace-like is formed [55]. Further increases of the iron ions relative to nickel ions, push the isotropic particle growth with the appearance of oxides layers with an iron molar ratio higher than $30 \%$ in which $\alpha$-Fe particles with low nickel content could be oxidized as confirmed by XRD. Conversely, iron can be oxidized faster than nickel; a faster growth leads to a similar growth rate of various facets and isotropic spheres, which was obtained. Also, a deviation from Vegard's law was recorded for an iron molar ratio higher than $30 \%$, in which superstructure phase of $\mathrm{FeNi}_{3}$ was formed and the presence of defects in it, as well as the dimensional effects of nanocrystals [56].

The role of metal concentration in controlling the morphology of the alloy particles can be attributed to (1) the generation rate of iron and nickel atoms and therefore the growth rate of alloy particles and (2) the molar ratio of free $\mathrm{OH}^{-} /\left(\mathrm{Fe}^{2+}\right.$ and $\left.\mathrm{Ni}^{2+}\right)$ ions in the reaction solution. An increase in iron ion concentration in the alloys results in an increasing trend in Ms, while Hc decreases proportionally. 
This work provides a simple, effective, and low-cost synthetic method to prepare stoichiometric $\mathrm{FeNi}_{3}$ alloy.

\section{Conclusions}

Nanostructured magnetic materials are highlighted due to their unique properties such as superparamagnetic, high magnetic anisotropy and coercivity, and giant magnetoresistance. These phenomena arise from finite size and surface effects in which the microstructure of materials has much influence on their physical and chemical properties. Nanocrystalline iron-nickel alloy receives attention because of its remarkable ferromagnetic properties and unique mechanical characteristics. Although it is possible to prepare the nanostructured alloy from iron and nickel in different ways, most of these methods suffer from problems that may reduce the purity of the resulting alloy and affect its magnetic properties.

In this work, iron-nickel nanostructure alloys with particle sizes in the range 77-532 nm have been successfully prepared via simple chemical reduction, which is characterized by simplicity, low cost, and easy control of the preparation conditions. In addition, no surfactants, templates, or organic solvents were used either for the preparation or washing process.

The nanostructured $\mathrm{Fe}_{10} \mathrm{Ni}_{90}$ alloy, which is characterized by the distinctive sea starfish-like shape with high magnetic and unique morphological properties and with a reaction time not exceeding $15 \mathrm{~min}$, was investigated. The length and width of the cones/needles increase in diminutions with an increase in the volume of the reaction mixture or the concentration of the metal. The prepared alloy is also characterized by high purity $(99.9 \%)$ as well as high stability due to the low concentration of rapidly oxidizing iron in the mixture, which gives it superior magnetic properties that enables it to be used in multiple applications such as medical and environmental applications such as removing water pollutants, and separating gases, etc.

The morphology of the synthesized alloy significantly changed with the initial molar ratio of metal ions. A deviation from Vegard's law was recorded for an iron molar ratio higher than $30 \%$, in which the superstructure phase of $\mathrm{FeNi}_{3}$ was formed and the presence of defects in it, as well as the dimensional effects of nanocrystals.

A remarkable change (improvement) in the magnetic properties of the alloy with an increase in the volume of the reaction solution was recorded. Increases in the total metal concentration decrease the coercivity $(\mathrm{Hc})$ of the synthesized alloy. The prepared nanostructures and magnetic properties have many potential applications in nanoscience and material fields due to their scientific value.

Author Contributions: Conceptualization, N.N.; methodology, N.N. and M.A.A.M.; software, N.N. and N.S.; formal analysis, N.N. and M.A.A.M.; investigation, N.N.; resources, N.N.; data curation, N.N., M.A.A.M. and N.S.; writing — original draft preparation, N.N.; writing — review and editing, N.N. and S.H.K.; supervision, N.N. and S.H.K.; final version review, N.N. and S.H.K. All authors have read and agreed to the published version of the manuscript.

Funding: This work was supported financially by The Science, Technology and Innovation Funding Authority (STDF), Egypt, Grant No. 37265.

Data Availability Statement: All data generated or analyzed during this study are included in this published article.

Conflicts of Interest: The authors declare no conflict of interest.

\section{References}

1. Kaur, R.; Hasan, A.; Iqbal, N.; Alam, S.; Saini, M.K.; Raza, S.K. Synthesis and surface engineering of magnetic nanoparticles for environmental cleanup and pesticide residue analysis: A review. J. Sep. Sci. 2014, 37, 1805-1825. [CrossRef] [PubMed]

2. Hedayatnasab, Z.; Abnisa, F.; Daud, W.M.A.W. Review on magnetic nanoparticles for magnetic nanofluid hyperthermia application. Mater. Des. 2017, 123, 174-196. [CrossRef] 
3. Zhou, K.; Zhou, X.; Liu, J.; Huang, Z. Application of magnetic nanoparticles in petroleum industry: A review. J. Pet. Sci. Eng. 2020, 188, 106943. [CrossRef]

4. Jiang, B.; Lian, L.; Xing, Y.; Zhang, N.; Chen, Y.; Lu, P.; Zhang, D. Advances of magnetic nanoparticles in environmental application: Environmental remediation and (bio) sensors as case studies. Environ. Sci. Pollut. Res. 2018, 25, 30863-30879. [CrossRef] [PubMed]

5. Coricovac, D.-E.; Moacă, E.-A.; Pinzaru, I.; Cîtu, C.; Soica, C.; Mihali, C.-V.; Păcurariu, C.; Tutelyan, V.A.; Tsatsakis, A.; Dehelean, C.-A. Biocompatible Colloidal Suspensions Based on Magnetic Iron Oxide Nanoparticles: Synthesis, Characterization and Toxicological Profile. Front. Pharmacol. 2017, 8, 154. [CrossRef]

6. Kongsat, P.; Kudkaew, K.; Tangjai, J.; Edgar, A.; Pongprayoon, T. Synthesis of structure-controlled hematite nanoparticles by a surfactant-assisted hydrothermal method and property analysis. J. Phys. Chem. Solids 2021, 148, 109685. [CrossRef]

7. Hudson, R.; Feng, Y.; Varma, R.S.; Moores, A. Bare magnetic nanoparticles: Sustainable synthesis and applications in catalytic organic transformations. Green Chem. 2014, 16, 4493-4505. [CrossRef]

8. Fatima, H.; Kim, K.-S. Iron-based magnetic nanoparticles for magnetic resonance imaging. Adv. Powder Technol. 2018, 29, 2678-2685. [CrossRef]

9. Zhou, Z.; Yang, L.; Gao, J.; Chen, X. Structure-relaxivity relationships of magnetic nanoparticles for magnetic resonance imaging. Adv. Mater. 2019, 31, 1804567. [CrossRef] [PubMed]

10. Harada, M.; Kuwa, M.; Sato, R.; Teranishi, T.; Takahashi, M.; Maenosono, S. Cation Distribution in Monodispersed $\mathrm{MFe}_{2} \mathrm{O}_{4}(\mathrm{M}=$ $\mathrm{Mn}, \mathrm{Fe}, \mathrm{Co}, \mathrm{Ni}$, and $\mathrm{Zn}$ ) Nanoparticles Investigated by X-ray Absorption Fine Structure Spectroscopy: Implications for Magnetic Data Storage, Catalysts, Sensors, and Ferrofluids. ACS Appl. Nano Mater. 2020, 3, 8389-8402. [CrossRef]

11. Döpke, C.; Grothe, T.; Steblinski, P.; Klöcker, M.; Sabantina, L.; Kosmalska, D.; Blachowicz, T.; Ehrmann, A. Magnetic nanofiber mats for data storage and transfer. Nanomaterials 2019, 9, 92. [CrossRef] [PubMed]

12. Gloag, L.; Mehdipour, M.; Chen, D.; Tilley, R.D.; Gooding, J.J. Advances in the application of magnetic nanoparticles for sensing. Adv. Mater. 2019, 31, 1904385. [CrossRef] [PubMed]

13. Matatagui, D.; Kolokoltsev, O.; Qureshi, N.; Mejía-Uriarte, E.; Ordoñez-Romero, C.; Vázquez-Olmos, A.; Saniger, J. Magnonic sensor array based on magnetic nanoparticles to detect, discriminate and classify toxic gases. Sens. Actuators B Chem. 2017, 240, 497-502. [CrossRef]

14. Jia, Z.; Kou, K.; Yin, S.; Feng, A.; Zhang, C.; Liu, X.; Cao, H.; Wu, G. Magnetic Fe nanoparticle to decorate N dotted C as an exceptionally absorption-dominate electromagnetic shielding material. Compos. Part B Eng. 2020, 189, 107895. [CrossRef]

15. Liang, L.; Yang, R.; Han, G.; Feng, Y.; Zhao, B.; Zhang, R.; Wang, Y.; Liu, C. Enhanced Electromagnetic Wave-Absorbing Performance of Magnetic Nanoparticles-Anchored 2D Ti3C2T x MXene. ACS Appl. Mater. Interfaces 2019, 12, $2644-2654$. [CrossRef]

16. Zhong, X.; Chen, J.; Wang, L.; Li, B.; Li, L. Properties of FeSiAl-based soft magnetic composites with $\mathrm{AlN} / \mathrm{Al}_{2} \mathrm{O}_{3}$ and hybrid phosphate-silane insulation coatings. J. Alloy. Compd. 2018, 735, 1603-1610. [CrossRef]

17. Mohapatra, J.; Xing, M.; Elkins, J.; Beatty, J.; Liu, J.P. Extraordinary Magnetic Hardening in Nanowire Assemblies: The Geometry and Proximity Effects. Adv. Funct. Mater. 2021, 31, 2010157. [CrossRef]

18. Bashir-U-Din, A. Characterisation of amorphous metal materials for high-frequency high-power-density transformer. In Proceedings of the 2018 26th International Conference on Systems Engineering (ICSEng), Sydney, Australia, 18-20 December 2018; IEEE: Washington, DC, USA, 2018.

19. Wang, S.; Sun, N.; Yamaguchi, M.; Yabukami, S. Properties of a new soft magnetic material. Nature 2000, 407, 150-151. [CrossRef]

20. Pardavi-Horvath, M. Microwave applications of soft ferrites. J. Magn. Magn. Mater. 2000, 215, 171-183. [CrossRef]

21. Lee, S.-Y.; Lim, Y.-S.; Choi, I.-H.; Lee, D.-I.; Kim, S.-B. Effective combination of soft magnetic materials for magnetic shielding. IEEE Trans. Magn. 2012, 48, 4550-4553. [CrossRef]

22. Jiles, D. Recent advances and future directions in magnetic materials. Acta Mater. 2003, 51, 5907-5939. [CrossRef]

23. Krajewski, M.; Tokarczyk, M.; Stefaniuk, T.; Słomińska, H.; Małolepszy, A.; Kowalski, G.; Lewińska, S.; Ślawska-Waniewska, A. Magnetic-field-induced synthesis of amorphous iron-nickel wire-like nanostructures. Mater. Chem. Phys. 2020, $246,122812$. [CrossRef]

24. Wu, K.-L.; Yu, R.; Wei, X.-W. Monodispersed $\mathrm{FeNi}_{2}$ alloy nanostructures: Solvothermal synthesis, magnetic properties and size-dependent catalytic activity. CrystEngComm 2012, 14, 7626-7632. [CrossRef]

25. Malaeru, T.; Patroi, E.A.; Patroi, D.; Manta, E.; Marinescu, V.; Georgescu, G. Influence of Synthesis Parameters of FeNi ${ }_{3}$ Alloy Nanoparticles Obtained by Chemical Reduction Method in Aqueous Solution. Rev. Chim. 2019, 70, 1118-1124. [CrossRef]

26. Gurmen, S.; Ebin, B.; Stopić, S.; Friedrich, B. Nanocrystalline spherical iron-nickel (Fe-Ni) alloy particles prepared by ultrasonic spray pyrolysis and hydrogen reduction (USP-HR). J. Alloy. Compd. 2009, 480, 529-533. [CrossRef]

27. Mohamed, M.A.; El-Maghraby, A.H.; Abd El-Latif, M.M.; Farag, H.A. Optimum synthesis conditions of nanometric Fe ${ }_{50} \mathrm{Ni}_{50}$ alloy formed by chemical reduction in aqueous solution. Bull. Mater. Sci. 2013, 36, 845-852. [CrossRef]

28. Yuan, Y.; Wu, H.; You, M.; Li, Z.; Zhang, Y. Improving wear resistance and friction stability of FeNi matrix coating by in-situ multi-carbide WC-TiC via PTA metallurgical reaction. Surf. Coat. Technol. 2019, 378, 124957. [CrossRef]

29. Ban, I.; Drofenik, M.; Makovec, D. The synthesis of iron-nickel alloy nanoparticles using a reverse micelle technique. J. Magn. Magn. Mater. 2006, 307, 250-256. [CrossRef] 
30. Tanaka, A.; Yoon, S.-H.; Mochida, I. Formation of fine Fe-Ni particles for the non-supported catalytic synthesis of uniform carbon nanofibers. Carbon 2004, 42, 1291-1298. [CrossRef]

31. Feng, C.; Liu, X.; Sun, Y.; Jin, C.; Lv, Y. Enhanced microwave absorption of flower-like FeNi@ C nanocomposites by dual dielectric relaxation and multiple magnetic resonance. RSC Adv. 2014, 4, 22710-22715. [CrossRef]

32. Cao, Y.; Gu, N.; Zhang, J.L. Synthesis and Characterization of Nanoscale Fe/Ni Alloy Particles by Hydrothermal Method. in Adv. Mater. Res. 2013, 658, 13-18. [CrossRef]

33. Liu, J.; Feng, Y.; Qiu, T. Synthesis, characterization, and microwave absorption properties of Fe-40 wt $\%$ Ni alloy prepared by mechanical alloying and annealing. J. Magn. Magn. Mater. 2011, 323, 3071-3076. [CrossRef]

34. Liu, L.; Guan, J.; Shi, W.; Sun, Z.; Zhao, J. Facile synthesis and growth mechanism of flowerlike Ni- Fe alloy nanostructures. J. Phys. Chem. C 2010, 114, 13565-13570. [CrossRef]

35. Maxwell, J.; Pegna, J.; Deangelis, D.; Messia, D. Three-dimensional laser chemical vapor deposition of nickel-iron alloys. MRS Online Proc. Libr. 1995, 397, 601-606. [CrossRef]

36. Davis, J. Materials for Medical Devices; ASM Handbook Series; ASM International: Materials Park, OH, USA, 2003.

37. Jin, M.; Zhou, W.; Jin, X.; Fukuda, T.; Kakeshita, T. Promoting martensitic transformation in Fe-Ni nanoparticles prepared by a Sol-gel and Reduction method. Mater. Lett. 2013, 109, 190-194. [CrossRef]

38. Yermekova, Z.; Roslyakov, S.I.; Kovalev, D.Y.; Danghyan, V.; Mukasyan, A.S. One-step synthesis of pure $\gamma$-FeNi alloy by reactive sol-gel combustion route: Mechanism and properties. J. Sol-Gel Sci. Technol. 2020, 94, 310-321. [CrossRef]

39. Dong, X.; Zhang, Z.; Zhao, X.; Chuang, Y.; Jin, S.; Sun, W. The preparation and characterization of ultrafine Fe-Ni particles. J. Mater. Res. 1999, 14, 398-406. [CrossRef]

40. Liu, Z.; He, F.; Gao, F.; Ren, B.; Huang, Y. Fabrication and electromagnetic properties of novel FeNi alloy-coated flake graphite prepared by electroless plating. J. Alloy. Compd. 2016, 656, 51-57. [CrossRef]

41. Jacob, G.A.; Sellaiyan, S.; Uedono, A.; Joseyphus, R.J. Magnetic properties of metastable bcc phase in $\mathrm{Fe}_{64} \mathrm{Ni}_{36}$ alloy synthesized through polyol process. Appl. Phys. A 2020, 126, 120. [CrossRef]

42. Beygi, H.; Babakhani, A. Microemulsion synthesis and magnetic properties of $\mathrm{Fe}_{\mathrm{x}} \mathrm{Ni}_{(1-\mathrm{x})}$ alloy nanoparticles. J. Magn. Magn. Mater. 2017, 421, 177-183. [CrossRef]

43. Yuan, M.L.; Tao, J.H.; Yu, L.; Song, C.; Qiu, G.Z.; Li, Y.; Xu, Z.H. Synthesis and magnetic properties of Fe-Ni alloy nanoparticles obtained by hydrothermal reaction. Adv. Mater. Res. 2011, 239-242, 748-753. [CrossRef]

44. Tong, G.; Yuan, J.; Wu, W.; Hu, Q.; Qian, H.; Li, L.; Shen, J. Flower-like Co superstructures: Morphology and phase evolution mechanism and novel microwave electromagnetic characteristics. CrystEngComm 2012, 14, 2071-2079. [CrossRef]

45. Wang, C.; Han, X.; Zhang, X.; Hu, S.; Zhang, T.; Wang, J.; Du, Y.; Wang, X.; Xu, P. Controlled synthesis and morphology-dependent electromagnetic properties of hierarchical cobalt assemblies. J. Phys. Chem. C 2010, 114, 14826-14830. [CrossRef]

46. Cullity, B.D. Elements of X-ray Diffraction; Addison-Wesley Publishing: Reading, MA, USA, 1956.

47. Amaliya, A.P.; Anand, S.; Pauline, S. Investigation on structural, electrical and magnetic properties of titanium substituted cobalt ferrite nanocrystallites. J. Magn. Magn. Mater. 2018, 467, 14-28. [CrossRef]

48. Islam, M.N.; Abbas, M.; Kim, C. Synthesis of monodisperse and high moment nickel-iron (NiFe) nanoparticles using modified polyol process. Curr. Appl. Phys. 2013, 13, 2010-2013. [CrossRef]

49. Guechi, N.; Bourzami, A.; Guittoum, A.; Kharmouche, A.; Colis, S.; Meni, N. Structural, magnetic and electrical properties of $\mathrm{Fe}_{\mathrm{x}} \mathrm{Ni}_{100-\mathrm{x}} / \mathrm{Si}$ (100) films. Phys. B Condens. Matter 2014, 441, 47-53. [CrossRef]

50. Denton, A.R.; Ashcroft, N.W. Vegard's law. Phys. Rev. A 1991, 43, 3161-3166. [CrossRef]

51. Wang, P.; Cui, C.; Yang, D.; Yu, X. Seed-assisted growth of cast-mono silicon for photovoltaic application: Challenges and strategies. Sol. RRL 2020, 4, 1900486. [CrossRef]

52. Yuwono, V.M.; Burrows, N.D.; Soltis, J.A.; Lee Penn, R. Oriented aggregation: Formation and transformation of mesocrystal intermediates revealed. J. Am. Chem. Soc. 2010, 132, 2163-2165. [CrossRef]

53. Johnson, D.; Pinski, F.; Staunton, J. The Slater-Pauling curve: First principles calculations of the moments of $\mathrm{Fe}_{1-\mathrm{c}} \mathrm{Ni}_{\mathrm{c}}$ and $\mathrm{V}_{1-\mathrm{c}}$ Fe. J. Appl. Phys. 1987, 61, 3715-3717. [CrossRef]

54. Dijith, K.S.; Aiswarya, R.; Praveen, M.; Pillai, S.; Surendran, K.P. Polyol derived Ni and NiFe alloys for effective shielding of electromagnetic interference. Mater. Chem. Front. 2018, 2, 1829-1841. [CrossRef]

55. Tripp, S.L.; Dunin-Borkowski, R.E.; Wei, A. Flux closure in self-assembled cobalt nanoparticle rings. Angew. Chem. Int. Ed. 2003, 42, 5591-5593. [CrossRef] [PubMed]

56. Kubo, S. Insights into the formation pathway of templated ordered nanostructured carbonaceous particles under hydrothermal conditions. Langmuir 2021, 37, 10866-10874. [CrossRef] [PubMed] 